\title{
A multifunctional human Argonaute2-specific monoclonal antibody
}

\author{
SABINE RÜDEL, ${ }^{1}$ ANDREW FLATLEY, ${ }^{2}$ LASSE WEINMANN, ${ }^{1}$ ELISABETH KREMMER, ${ }^{2}$ and GUNTER MEISTER ${ }^{1}$ \\ ${ }^{1}$ Center for Integrated Protein Science Munich (CIPSM), Laboratory of RNA Biology, Max Planck Institute of Biochemistry, \\ 82152 Martinsried, Germany \\ ${ }^{2}$ Helmholtz Center Munich, Institute of Molecular Immunology, 81377 Munich, Germany
}

\begin{abstract}
Small regulatory RNAs including small interfering RNAs (siRNAs), microRNAs (miRNAs), or Piwi interacting RNAs (piRNAs) guide regulation of gene expression in many different organisms. The Argonaute (Ago) protein family constitutes the cellular binding partners of such small RNAs and regulates gene expression on the levels of transcription, mRNA stability, or translation. Due to the lack of highly specific and potent monoclonal antibodies directed against the different Ago proteins, biochemical analyses such as Ago complex purification and characterization rely on overexpression of tagged Ago proteins. Here, we report the generation and functional characterization of a highly specific monoclonal anti-Ago2 antibody termed anti-Ago2(11A9). We show that anti-Ago2(11A9) is specific for human Ago2 and detects Ago2 in Western blots as well as in immunoprecipitation experiments. We further demonstrate that Ago2 can be efficiently eluted from our antibody by a competing peptide. Finally, we show that anti-Ago2(11A9) recognizes Ago2 in immunofluorescence experiments, and we find that Ago2 not only localizes to cytoplasmic processing bodies (P-bodies) and the diffuse cytoplasm but also to the nucleus. With the anti-Ago2(11A9) antibody we have generated a potent tool that is useful for many biochemical or cell biological applications.
\end{abstract}

Keywords: Argonaute proteins; microRNAs; RISC; RNAi; gene silencing

\section{INTRODUCTION}

RNA silencing, or RNA interference (RNAi), is an evolutionarily conserved gene silencing pathway that is triggered by dsRNA (Meister and Tuschl 2004). The dsRNA trigger molecules are processed to small interfering RNAs (siRNAs) or microRNAs (miRNAs), which are then assembled into various silencing effector complexes, including the RNAinduced silencing complex (RISC) (Meister and Tuschl 2004; Filipowicz et al. 2005; Zamore and Haley 2005). Effector complexes containing miRNAs are often referred to as miRNPs (Mourelatos et al. 2002). miRNA precursors (pre-miRNAs) are excised from primary transcripts by a nuclear endonucleolytic complex that contains the RNase III enzyme Drosha and the dsRNA-binding domain (dsRBD) protein DGCR8/Pasha (Chen and Meister 2005; Zamore and Haley 2005). Pre-miRNAs are subsequently exported to the cytoplasm by the export receptor Exportin5

Reprint requests to: Gunter Meister, Center for Integrated Protein Science Munich (CIPSM), Laboratory of RNA Biology, Max Planck Institute of Biochemistry, Am Klopferspitz 18, 82152 Martinsried, Germany; e-mail: meister@biochem.mpg.de; fax: +49 85783430.

Article published online ahead of print. Article and publication date are at http://www.rnajournal.org/cgi/doi/10.1261/rna.973808. for further maturation (Chen and Meister 2005; Zamore and Haley 2005). In the cytoplasm, dsRNA and premiRNAs are processed by the RNase III enzyme Dicer to duplexes of $\sim 21-23$ nucleotides (nt) (Meister and Tuschl 2004). Similar to Drosha, Dicer functions in concert with dsRBD proteins as well. In humans, the immunodeficiency virus trans-activating response RNA-binding protein (TRBP) interacts with Dicer and contributes to the processing of miRNA precursors (Chendrimada et al. 2005; Haase et al. 2005). Recently, the dsRBD protein PACT has been shown to functionally interact with human Dicer as well (Lee et al. 2006). In a subsequent assembly process, which is not yet fully understood and presumably involves the action of ATP dependent helicases, only one strand of the siRNA or miRNA duplex intermediate is loaded into the silencing effector complex to become the guide sequence (Meister and Tuschl 2004). Notably, the putative RNA helicases RNA Helicase A (RHA) as well as DDX5/p68 have recently been implicated in RISC loading (Robb and Rana 2007; Salzman et al. 2007). An alternative model for RISC loading and activation has been proposed. In this model, the sense strand of the siRNA (also termed nonguide or passenger strand) is cleaved by Ago2, and the short 10to 12-nt long cleavage products dissociate from the RISC 
presumably without the help of helicases (Matranga et al. 2005; Rand et al. 2005; Leuschner et al. 2006). The identification of a complex consisting of Ago2, TRBP, and Dicer that can be loaded with dsRNA or pre-miRNAs without the help of assisting helicases supports the above-mentioned RISC loading model (Gregory et al. 2005). However, the loading of endonucleolytically inactive human Ago1, Ago3, and Ago4 complexes is not explained by such a model and presumably involves different pathways.

Depending on the complementarity between the small guide RNA and its target, siRNAs and miRNAs guide either the sequence-specific degradation of complementary RNA molecules or inhibit the translation of partially complementary target mRNAs (Pillai et al. 2007). Recently, a third pathway of miRNA function has been identified in Drosophila and zebrafish, in which miRNAs guide the degradation of imperfectly complementary target mRNAs by recruiting deadenylation and decapping enzymes (BehmAnsmant et al. 2006; Giraldez et al. 2006).

Members of the Ago protein family are key components of RNA silencing effector complexes. Ago proteins contain piwi-argonaute-zwille (PAZ) and PIWI domains (Carmell et al. 2002; Peters and Meister 2007; Hutvagner and Simard 2008). Recently, structures of PIWI domains, isolated PAZ domains, as well as full-length archaeal Ago proteins have been solved by NMR and X-ray crystallography (Hall 2005; Parker and Barford 2006; Patel et al. 2006; Song and Joshua-Tor 2006). The PIWI domain structures of bacterial proteins revealed striking similarity to RNase $\mathrm{H}$, and it has been demonstrated that these proteins contain endonucleolytic activity (Parker et al. 2004; Song et al. 2004). Studies on human Ago proteins revealed that Ago2 is the endonuclease that cleaves the target RNA in RNAi (Liu et al. 2004; Meister et al. 2004). The MID domain, which is located N-terminally of the PIWI domain, forms the $5^{\prime}$ phosphate binding pocket for the small RNA that sets the register for target RNA cleavage (Ma et al. 2005; Parker et al. 2005). Recently, a conserved tyrosine residue within this binding pocket has been implicated in protein-protein interaction as well (Till et al. 2007). The previously characterized PAZ domain of Ago proteins specifically recognizes and binds the single-stranded $3{ }^{\prime}$ ends of small RNAs (Hall 2005; Song and Joshua-Tor 2006).

Besides Ago proteins as core components of RNA silencing effector complexes, additional proteins have been identified in different experimental systems (for review, see Peters and Meister 2007). In humans, interactions of Ago2 with FMRP (fragile X mental retardation protein) have been observed (Jin et al. 2004). Furthermore, human miRNAs reside in a defined $15 \mathrm{~S}$ complex that contains Gemin3, Gemin4, and Ago2 (Mourelatos et al. 2002). Recently, biochemical purifications of Agol and Ago2 complexes from HeLa cell lysates identified the $\mathrm{DExD}$ box protein MOV10 and a protein termed TNRC6B as novel Ago complex components. The precise function of these different proteins in the RNA silencing process, however, remains elusive (Meister et al. 2005). Interestingly, TNRC6B is highly homologous with TNRC6A (GW182), which has been implicated in small RNA-guided gene silencing in many different organisms and constitutes a marker protein for P-bodies (Ding et al. 2005; Jakymiw et al. 2005; Liu et al. 2005a; Behm-Ansmant et al. 2006). P-bodies are cellular sites of RNA metabolism (Eulalio et al. 2007a), and it has been shown that Ago proteins localize to P-bodies as well (Liu et al. 2005b; Meister et al. 2005; Sen and Blau 2005). Further studies revealed that miRNAs as well as target mRNAs are also found in P-bodies, and it has been suggested that localization of mRNAs to P-bodies may prevent their translation (Liu et al. 2005b; Pillai et al. 2005; Bhattacharyya et al. 2006). However, it has also been shown that P-bodies form as a consequence of miRNA-guided gene silencing but are not required for it (Eulalio et al. 2007b).

In human cells, Ago proteins are found in different protein complexes with distinct molecular weights (Martinez et al. 2002; Mourelatos et al. 2002; Hock et al. 2007). Furthermore, Ago proteins are embedded into large mRNA-protein structures, and it has been shown that miRNA-targeted mRNAs can be isolated and identified from purified Ago complexes (Beitzinger et al. 2007; Easow et al. 2007; Karginov et al. 2007). In combination with bioinformatic miRNA target prediction algorithms, such biochemical approaches provide a novel tool for fast and reliable miRNA target identification. However, due to the lack of potent and highly specific antibodies against human Ago proteins, many biochemical studies rely on overexpression of a tagged Ago version, which sometimes interferes with natural protein function.

Here, we report the generation and functional characterization of a monoclonal anti-Ago 2 antibody. This antibody recognizes human Ago2 in Western blots and does not cross-react with other human Ago proteins. Furthermore, we demonstrate that the anti-Ago 2 antibody specifically immunoprecipitates Flag/HA-tagged as well as endogenous Ago2 without precipitating other Ago proteins. Moreover, we show that bound Ago2 can be efficiently eluted from the antibody matrix by competition with a short peptide comprising the epitope of the antibody. Finally, we demonstrate that the anti-Ago2 antibody recognizes cellular Ago 2 in immunofluorescence studies by presenting data on endogenous Ago2 distribution without overexpression.

\section{RESULTS}

\section{Anti-Ago2(11A9) discriminates between Ago2 and other human Ago proteins in Western blots}

Due to the lack of potent and specific antibodies, most of the biochemical studies on human Ago proteins used overexpressed, tagged Ago proteins. In order to better understand endogenous RISC function, we set out to 
generate a specific monoclonal anti-Ago2 antibody. A peptide encompassing the very $\mathrm{N}$-terminal end of human Ago2 that is not conserved in other human Ago proteins (Fig. 1A) was injected into rats for monoclonal antibody production. We obtained hybridoma clone 11A9, which reacted strongly in an initial ELISA screen coated with the injected peptide (data not shown). Next, we analyzed antiAgo2(11A9) in Western blots. Flag/HA-tagged Ago1 through 4 (FH-Ago) were expressed in HEK 293 cells and immunoprecipitated using anti-Flag antibody-coated agarose beads (Fig. 1B). Similar amounts of FH-Ago1-4 as well as FH-GFP were blotted onto nitrocellulose membranes and subsequently probed with anti-HA (Fig. 1B, lanes 712) or anti-Ago2(11A9) antibodies (Fig. 1B, lanes 1-6). Strikingly, anti-Ago2(11A9) strongly reacted with FH-Ago2 in Western blots (Fig. 1B, lane 2), whereas FH-Ago1, 3, 4, or FH-GFP were not detected by the antibody. Similar results were obtained using myc-tagged Ago proteins (Fig. $1 \mathrm{~B}$, lanes 13-24), indicating that anti-Ago2(11A9) is highly specific for Ago2 in Western blots.

Next, we investigated the Western blotting specificity of anti-Ago2(11A9) in lysates from untreated cells (Fig. 1C). Total cell lysates from RPE-1, HEK 293, and HeLa cells were analyzed using anti-Ago2(11A9) (Fig. 1C, lanes 1-3). Anti-Ago2(11A9) detected one single band with a molecular weight of $\sim 100 \mathrm{kDa}$, indicating that the antibody is highly specific for endogenous Ago2 as well. No signal was observed when lysate from the mouse neuroblastoma cell line N2A was analyzed, demonstrating that antiAgo2(11A9) does not recognize mouse Ago2. For further validation of the antibody, we separated nuclear and cytoplasmic extracts from the above-mentioned cell lines (Fig. 1C, lanes 5-12). Consistently, anti-Ago2(11A9) recognized specifically Ago2 in the cytoplasmic fractions. Interestingly, Ago 2 is also detected in the nuclear fractions, suggesting putative roles of Ago2 in the nucleus or associated cellular compartments. Notably, two additional bands of unknown identity were detected in the nuclear fractions, which most likely reflect cross-reactivity with nuclear proteins. However, these bands were not detected in total cell lysates, presumably due to lower amounts of nuclear proteins therein. Using anti-Ago2(11A9), we analyzed endogenous Ago2 levels in a variety of cell lines (Fig. 1D). Interestingly, anti-Ago2(11A9) detects an additional band migrating slower than Ago2 in some cell lines, which most likely reflects post-translational modification of Ago2.

In summary, we have generated a monoclonal antibody that is highly specific for human Ago2 in Western blots. This antibody is available form www.ascenion.de.

\section{Anti-Ago2(11A9) specifically immunoprecipitates human RISC}

In order to perform biochemical studies on endogenous RISC, we analyzed anti-Ago2(11A9) for its immunoprecip-
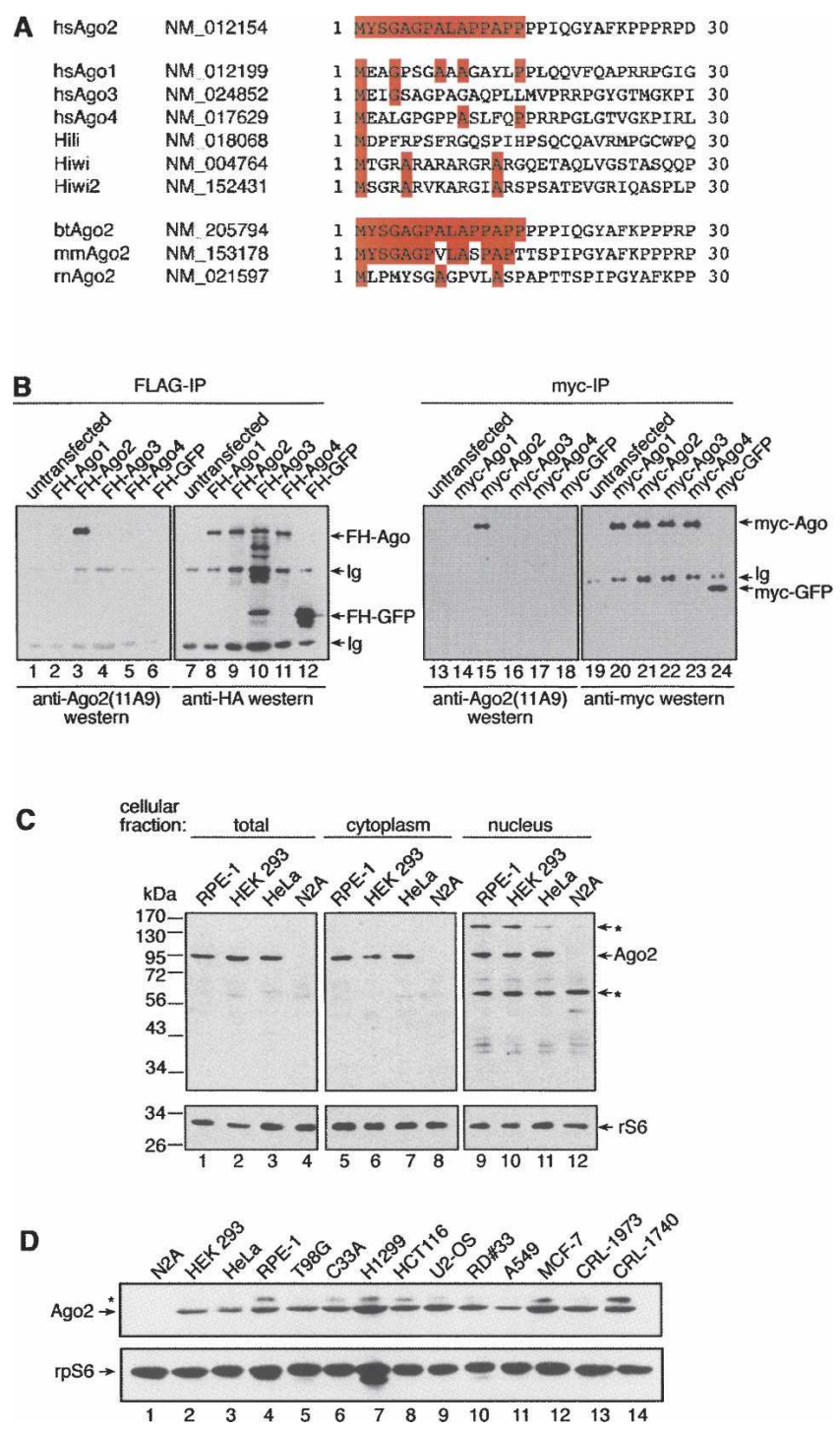

FIGURE 1. Anti-Ago2(11A9) is Ago2-specific in Western blots. (A) Amino acid alignment of the Ago2 peptide used for antibody generation. (B) Flag/HA-tagged Agol (FH-Agol) through FH-Ago4 (lanes 1-5,7-11), FH-GFP (lanes 6,12), myc-Agol through 4 (lanes 13-17,19-23), and myc-GFP (lanes 18,24) were expressed in HEK 293 cells and immunoprecipitated using anti-Flag or anti-myc antibodies. Blotted immunoprecipitates were probed with anti-Ago2(11A9) (lanes 1-6,13-18), anti-HA (lanes 7-12), or anti-myc antibodies (lanes 19-24). Ig indicates heavy and light chains of the immunoglobulins. (C) $30 \mu \mathrm{g}$ of total cell lysate (lanes 1-4), cytoplasmic extract (lanes 5-8), or nuclear extract (lanes 9-12) from RPE-1, HEK 293, or HeLa cells was blotted and probed with anti-Ago2(11A9). A Western blot using antibodies against the ribosomal protein S6 (rS6) served as a loading control (lower panel). (Asterisks) Unidentified proteins. (D) Total cell lysate from various cell lines was analyzed using anti-Ago2(11A9) (upper panel) or anti-rS6 (lower panel) as loading control. (Asterisk) Additional band recognized by anti-Ago2(11A9), which might correspond to post-translational modifications. 
itation capabilities. Myc-tagged Agol through 4 were expressed in HEK 293 cells, and the lysates were subjected to anti-Ago2(11A9) immunoprecipitation (Fig. 2A). Immunoprecipitated proteins were further analyzed by Western blotting using anti-myc antibodies. The monoclonal antiAgo2(11A9) antibody readily immunoprecipitated mycAgo2 (Fig. 2A, lane 6) whereas no myc-Ago1, myc-Ago3, or myc-Ago4 (Fig. 2A, lanes 5,7,8) was immunoprecipitated. Our results clearly show that anti-Ago2(11A9) specifically recognizes and efficiently immunoprecipitates

A

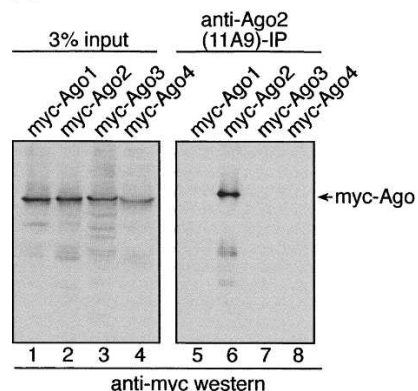

B

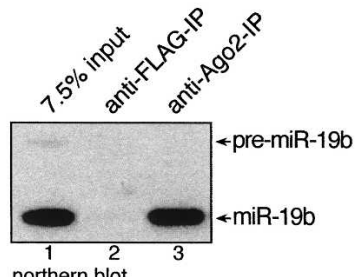

northern blot

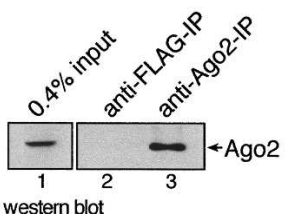

C

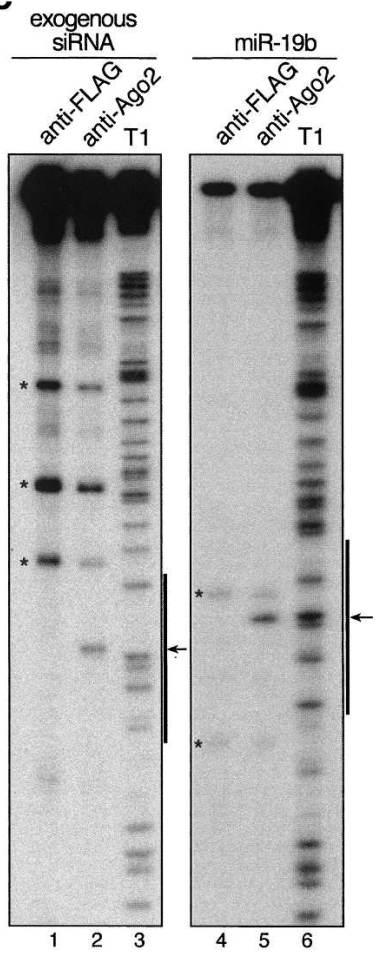

FIGURE 2. Anti-Ago2(11A9) specifically immunoprecipitates human Ago2 and therefore RISC. (A) myc-Ago1 through myc-Ago4 were expressed in HEK 293 cells and immunoprecipitated with antiAgo2(11A9) (lanes 5-8). Immunoprecipitated proteins were analyzed by Western blotting using anti-myc antibodies. (Lanes $1-4$ ) $3 \%$ of the lysate that has been used for the immunoprecipitations. (B) Endogenous Ago2 was immunoprecipitated from HEK 293 cell lysates using anti-Ago2(11A9) (lane 3). Associated RNA was extracted and analyzed by Northern blotting using a probe specific for the endogenous miR-19b (upper panel), while immunoprecipitated proteins were analyzed by Western blotting using anti-Ago2(11A9) (lower panel). An anti-Flag antibody served as negative control (lane 2). (Lane 1) $7.5 \%$ or $0.4 \%$ input. (C) Anti-Ago2(11A9) (lanes 2,5) or anti-Flag antibodies (lanes 1,4) were used for immunoprecipitation from untreated HEK 293 cell lysates. Immunoprecipitates were either preincubated with a single-stranded siRNA (lanes 1,2) or directly used for cleavage assays (lanes 4,5). ${ }^{32} \mathrm{P}$-cap-labeled RNAs containing complementary target sites for the siRNA (lanes 1-3) or endogenous miR-19b (lanes 4-6) were used as RISC target RNAs. The cleavage products were analyzed by denaturing RNA PAGE followed by autoradiography. (T1 lanes) Nuclease T1 digestion of the substrate RNA. The small RNA target sites are indicated (black bars to the right of the gels), and the individual cleavage positions are marked (arrows). (Asterisks) Unspecific degradation products.

myc-Ago2 and is therefore a valuable tool for biochemical analysis of human RISC.

Ago proteins are known to bind miRNAs (Peters and Meister 2007; Hutvagner and Simard 2008). Ago complex isolation followed by small RNA cloning and sequencing can be a useful tool for small RNA profiling in different cell lines or primary tissues, because Ago association indicates functional small RNA classes and clearly discriminates them from cellular RNA degradation products. Therefore, we analyzed if anti-Ago2(11A9) coimmunoprecipitates endogenous miRNAs. HEK 293 lysates were subjected to immunoprecipitation using anti-Ago2(11A9) (Fig. 2B). The coprecipitated RNA was separated by denaturing RNA PAGE and analyzed by Northern blotting using a probe complementary to miR-19b. MiR-19b was detectable in the total RNA sample (Fig. 2B, lane 1) and in the anti-Ago2(11A9) coimmunoprecipitate (Fig. 2B, lane 3). No miR-19b signal was observed in the anti-Flag control immunoprecipitation (Fig. 2B, lane 2). Similar results were obtained for many other miRNAs present in HEK 293 cells (data not shown).

It has been reported earlier that human Ago2 is the catalytic subunit of RISC (Liu et al. 2004; Meister et al. 2004). In order to analyze if anti-Ago2(11A9) immunoprecipitates functional RISC from human cell lysates, we performed in vitro cleavage assays (Fig. 2C). Ago2 was immunoprecipitated from untreated HEK 293 cell lysates using anti-Ago2(11A9) and incubated with a ${ }^{32} \mathrm{P}$-caplabeled substrate RNA containing a fully complementary binding site for endogenous miR-19b. Strikingly, a specific RISC cleavage product was observed only in the antiAgo2(11A9) immunoprecipitate (Fig. 2C, lane 5), whereas no specific signal was detected in the control experiment (Fig. 2C, lane 4). Finally, we investigated if RISC activity can be reconstituted in vitro by using synthetic siRNAs in combination with anti-Ago2(11A9) immunoprecipitates (Fig. 2C). Endogenous Ago2 was immunoprecipitated using our monoclonal antibody and subsequently loaded with a synthetic single-stranded siRNA. The siRNA-primed Ago2 complex was further incubated with a radiolabeled target RNA containing a fully complementary target site for the synthetic siRNA. The immunoprecipitated Ago2 cleaved the target RNA (Fig. 2C, lane 2), whereas no specific cleavage signal was observed in the control immunoprecipitate (Fig. 2C, lane 1).

In summary, we have shown that our monoclonal antiAgo2(11A9) antibody discriminates between Ago2 and other human Ago proteins in immunoprecipitation experiments and immunoprecipitates active RISC from untreated human cell lysates.

\section{Native RISC isolation using peptide elution}

Biochemical studies on RISC function such as kinetic measurements or proteomics often require soluble and pure complex isolations. This can be achieved by specific 
elution of affinity-captured proteins by adding a peptide encompassing the antibody epitope. We therefore set out to establish a protocol for native elution of Ago2 from the anti-Ago2(11A9) antibody matrix (Fig. 3A). We expressed FH-Ago2 in HEK 293 cells and immunoprecipitated tagged Ago2 with anti-Ago2(11A9). After stringent washing, a peptide encompassing the epitope of anti-Ago2(11A9) was added to compete for antibody binding (Fig. 3A). After 90 min of incubation with the Ago2 peptide, a considerable amount of bound Ago2 was eluted from the column (Fig. 3B, upper panel, lane 4), whereas no Ago2 was detected when the competing peptide was omitted from the reaction (Fig. 3B, middle panel). Similar results were obtained when endogenous Ago2 was immunoprecipitated from wild-type

A

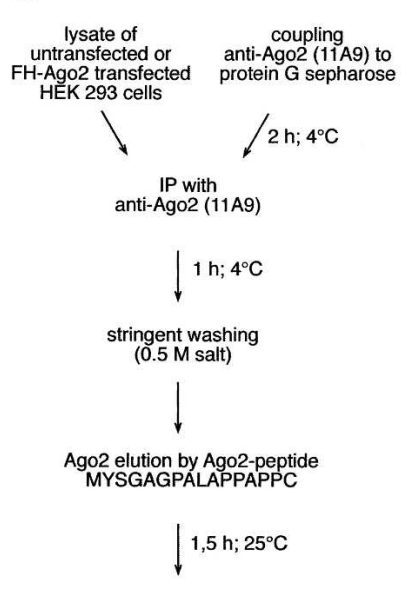

C

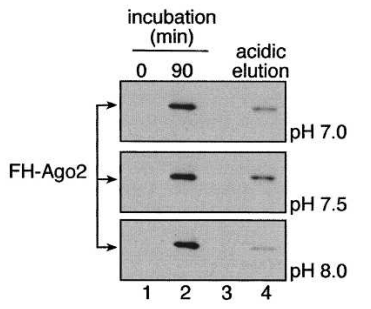

D

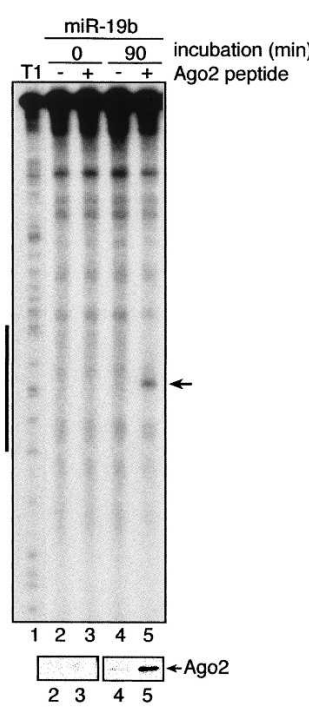

FIGURE 3. Peptide elution of Ago2 from anti-Ago2(11A9) antibodies. (A) Schematic representation of the experimental set up used in $B-D$. (B) FH-Ago2 was expressed in HEK 293 cells and immunoprecipitated using anti-Ago2(11A9). Antibody-bound Ago2 was incubated with (panel $i$ ) or without (panel ii) addition of an Ago2 peptide encompassing the anti-Ago2(11A9) epitope for the indicated time intervals. (Lane 6) Denaturing elution of remaining Ago2. In panel iii, untransfected HEK 293 cell lysate was used. (C) Experiments were performed as described in $B$ using $\mathrm{pH} 7$ (upper panel), $\mathrm{pH} 7.5$ (middle panel), or $\mathrm{pH} 8$ (lower panel) for elution. (D) Endogenous Ago2 was immunoprecipitated with anti-Ago2(11A9) and eluted as described in $B$. Eluates were incubated with a ${ }^{32} \mathrm{P}$-cap-labeled target RNA complementary to endogenous miR-19b, and RISC cleavage assays were performed as described in Fig. 2C. (Lower panel) Western blot of the eluates.
HEK 293 cells (Fig. 3B, lower panel). Since antibody interactions are often sensitive to slight $\mathrm{pH}$ shifts, we repeated the experiment described above using different $\mathrm{pH}$ conditions to identify the optimal $\mathrm{pH}$ range for efficient elution (Fig. 3C). Lowering the $\mathrm{pH}$ from 7.5 to 7.0 had only a minor effect on the elution efficiency. However, at $\mathrm{pH} 8.0$ almost all bound Ago2 was eluted from the column, indicating that RISC can be efficiently dissociated from the antiAgo2(11A9) antibody. We next investigated if RISC activity is maintained during the above-mentioned elution procedure (Fig. 3D). Therefore, peptide-eluted RISC was incubated with a target RNA complementary to endogenous miR-19b, and the cleavage products were analyzed by denaturing RNA PAGE. Strikingly, only in the reaction where eluted RISC was present was a specific cleavage product detectable (Fig. 3D, lane 5), demonstrating that Ago2 complexes can be efficiently eluted by peptide competition.

\section{Anti-Ago2(11A9) detects Ago2 in immunofluorescence experiments}

Cellular Ago localization studies using immunofluorescence have been performed using tagged and overexpressed human Ago proteins or sera that have not been tested for cross-reactivity with other Ago proteins (Jakymiw et al. 2005; Liu et al. 2005b; Meister et al. 2005; Sen and Blau 2005). In order to find an antibody that specifically recognizes endogenous Ago2, we tested anti-Ago2(11A9) in immunofluorescence experiments using confocal microscopy (Fig. 4). HEK 293 (upper panels), HeLa (middle panels), or RPE-1 cells (lower panels) were fixed and stained with anti-Ago2(11A9) and anti-LSm4 antibodies. LSm4 is a component of the cellular RNA degradation machinery and served as a marker protein for P-bodies. In all three cell types, anti-Ago(11A9) showed a diffuse cytoplasmic staining. Moreover, distinct cytoplasmic foci that can be costained with anti-LSm4 antibodies and therefore indicate P-bodies are clearly visible (white arrows). Only a very weak background staining was observed when anti-Ago2(11A9) was omitted from the experiment (Fig. 4, panels 13,14). Interestingly, the confocal images from all three cell types revealed a detectable nuclear staining. In order to rule out that the nuclear signals are caused by anti-Ago2(11A9) cross-reactivities observed in Western blots (Fig. 1B), we performed an Ago2 knock down prior to anti-Ago2(11A9) staining (Fig. 4B). Notably, both the cytoplasmic and the nuclear staining disappeared after Ago2 knock down, indicating that the signals observed in anti-Ago2(11A9) stainings represent intracellular Ago2 localization.

\section{DISCUSSION}

Human RISC or Ago protein complexes have been purified using different biochemical approaches. RISC has been reconstituted on biotinylated siRNAs, or tagged Ago 
A
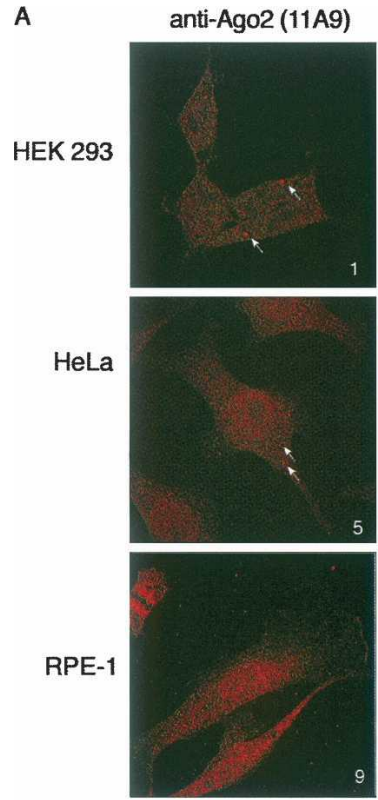

anti-rat (TexasRed)

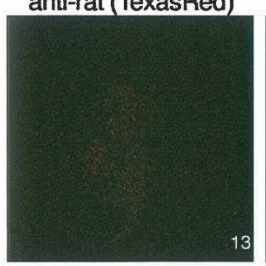

B
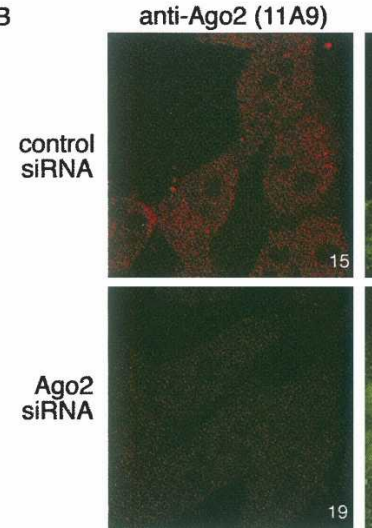
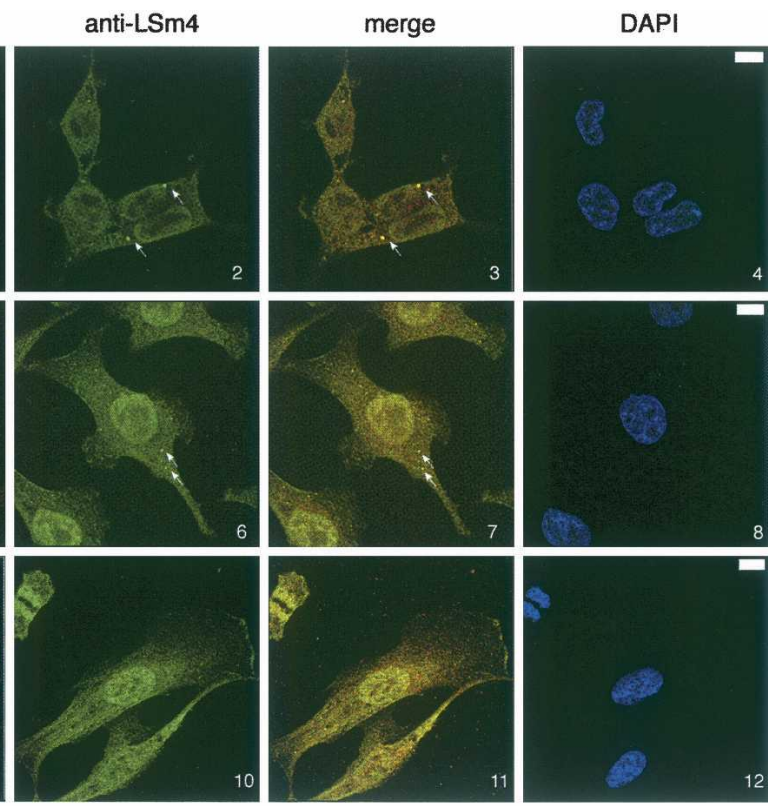

DAPI
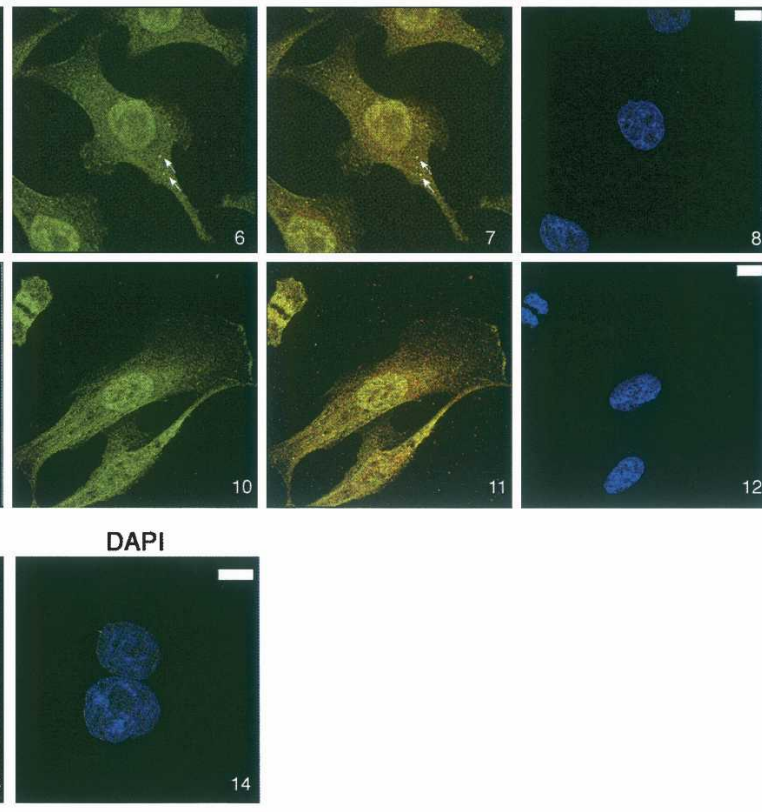

anti-LSm4
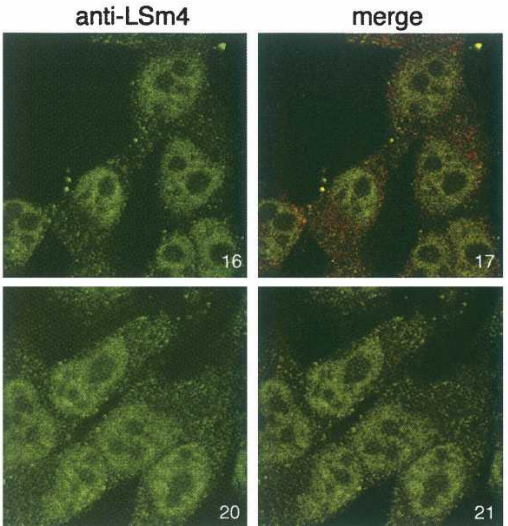

FIGURE 4. Anti-Ago2(11A9) detects endogenous Ago2 in immunofluorescence experiments. (A) HEK 293 cells (panels 1-4,13-14), HeLa cells (panels 5-8), or RPE-1 cells (panels 9-12) were fixed and stained with anti-Ago2(11A9) (panels 1,5,9,13) and anti-LSm4 antibodies (panels 2,6,10). (Panels 3,7,11) Merged images, (panels 4,8,12,14) DAPI staining. In panels 13 and 14, anti-Ago2(11A9) was omitted from the experiment. (B) HeLa cells were transfected with siRNAs against Ago2 (panels 19-22) or control siRNAs (panels 15-18). Cells were fixed and stained with anti-Ago2(11A9) (panels 15,19) or anti-LSm4 antibodies (panels 16,20). (Panels 18,22) DAPI stainings.

proteins were expressed and purified using affinity chromatography (Martinez et al. 2002; Gregory et al. 2005; Maniataki and Mourelatos 2005; Meister et al. 2005; Hock et al. 2007). Although these studies were very successful and key discoveries have been made, such approaches are for
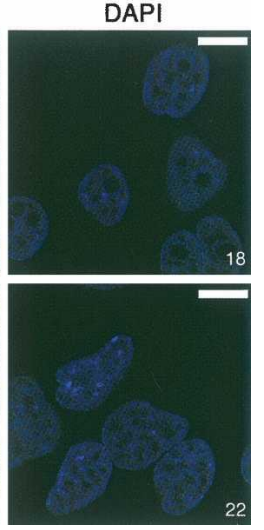

three main reasons not ideal. First, overexpression of tagged Ago proteins may cause artificial protein-protein interactions. Second, tagging of proteins may interfere with function. This has not been observed for RISC activity when Ago2 was N-terminally tagged. However, it cannot be excluded that the tag affects other as yet unknown Ago2 functions. Third, and most importantly, tagged Ago proteins can only be introduced into transfectable cell lines. Very often, purification from primary cells or even tissue samples is more conclusive. Therefore, we have generated the monoclonal anti-Ago2(11A9) antibody in order to be independent of transfection and overexpression. We show that our monoclonal antibody is specific for Ago2 and does not react with the other highly conserved human Ago proteins. Moreover, anti-Ago2(11A9) immunoprecipitates active RISC from untreated cell lysates with high efficiency, providing a useful tool for Ago2 complex isolation from cells or tissues.

In many affinity purification protocols, the elution from the affinity matrix is often a critical step, because denaturing conditions often result in the elution of contaminants as well that bind unspecifically to the column. Strikingly, Ago2 can be efficiently eluted from the anti-Ago2(11A9) antibody by adding a peptide encompassing the epitope of the antibody, thus competing for binding.

Various small RNA cloning and sequencing approaches have been performed in organisms as diverse as plants, nematodes, flies, and mammals. Most of these studies were aiming at the identification of novel or differentially regulated miRNAs. However, by cloning from total RNA, cellular degradation products and other so far unidentified classes of small RNAs are cloned and sequenced as well. It is very often difficult to distinguish between degradation products and functional classes of small RNAs. Therefore, we suggest that small RNA cloning approaches should be carried out from isolated Ago complexes, since associated small RNAs are most likely functional. Our monoclonal anti-Ago2 antibody provides a powerful tool for the identification of Ago2-associated functional small RNAs. Of 
course, for comprehensive studies on Ago-associated small RNAs, potent antibodies directed against human Ago1, Ago3, and Ago4 will have to be generated in the future.

Ago complex purifications have recently been used for the identification of miRNA targets (Beitzinger et al. 2007; Easow et al. 2007; Karginov et al. 2007). Together with bioinformatic studies, such biochemical miRNA target identification approaches will be widely used in the future. In particular, more and more miRNA profiling studies aiming for the identification of differentially expressed miRNAs are carried out in many types of human tumors. Our antibody therefore provides a tool for the identification of miRNA targets from such cancerous human tissue.

Immunofluorescence studies revealed that human Ago proteins localize to P-bodies (Jakymiw et al. 2005; Liu et al. 2005b; Meister et al. 2005; Sen and Blau 2005; Leung et al. 2006). In many studies, a diffuse cytoplasmic staining has been observed as well. Due to the lack of potent anti-Ago antibodies for immunofluorescence experiments, these studies have been carried out using either tagged Ago proteins or poorly characterized anti-Ago sera. Strikingly, anti-Ago2(11A9) clearly detects Ago2 in P-bodies as well as a diffuse Ago2 distribution in the cytoplasm. Surprisingly, we also observed a nuclear staining with our antibody. Since such nuclear stainings have not been observed before, we performed an Ago2 knock down and found that both the cytoplasmic and the nuclear staining was strongly reduced. We conclude that the nuclear signal that we have observed represents a nuclear Ago2 pool. Notably, small RNAs as well as Ago proteins have indeed been implicated in nuclear functions before. It has been shown that siRNAs or miRNAs directed against nuclear RNAs guide efficient RNAi in nuclear extracts (Meister et al. 2004; Robb et al. 2005). Moreover, it has been suggested that siRNAs as well as Ago proteins guide transcriptional silencing processes on specific promoters in the nucleus (Morris et al. 2004; Janowski et al. 2006; Kim et al. 2006).

Taken together, we have generated a specific and efficient antibody against human Ago2 that will be highly valuable for the scientific community. Anti-Ago2(11A9) is available from www.ascenion.de.

\section{MATERIALS AND METHODS}

\section{Cell lines and plasmids}

Plasmids encoding Flag/HA-tagged proteins were described previously (Meister et al. 2004). For the expression of myc-tagged proteins, the corresponding cDNAs were cloned into a modified pCS2 plasmid kindly provided by Olaf Stemmann (Max Planck Institute of Biochemistry, Germany).

\section{Cell culture and transfection}

All cell lines used in this study were cultured in Dulbecco's modified Eagle's medium (PAA) supplemented with glucose
$(4.5 \mathrm{~g} / \mathrm{L})$ and $10 \%(\mathrm{v} / \mathrm{v})$ fetal bovine serum (Biochrom AG) in the presence of penicillin and streptomycin (Gibco).

After transfection by calcium phosphate procedure (Meister et al. 2005), HEK 293 cells were grown for an additional $48 \mathrm{~h}$ in $5 \% \mathrm{CO}_{2}$ atmosphere without medium exchange.

\section{Extract preparations and Western blotting}

For total cell extract, cells were scraped off the culture plates in lysis buffer $(20 \mathrm{mM}$ Tris- $\mathrm{HCl}, \mathrm{pH} 7.5 ; 150 \mathrm{mM} \mathrm{NaCl} ; 0.5 \%$ Nonidet P-40; 2 mM EDTA; $0.5 \mathrm{mM}$ DTT; $1 \mathrm{mM} \mathrm{NaF}$; and $1 \mathrm{mM}$ Pefablock [Roche]) and centrifuged for $10 \mathrm{~min}$ at $17,000 \mathrm{~g}$.

Cytoplasmic and nuclear extract preparation according to Dignam et al. (1983) was modified as follows: Cells were trypsinized, washed once in PBS, resuspended in five volumes of hypotonic Roeder A buffer (10 mM HEPES, pH 7.9; $10 \mathrm{mM}$ $\mathrm{KCl} ; 1.5 \mathrm{mM} \mathrm{MgCl}_{2} ; 0.5 \mathrm{mM}$ DTT; and $1 \mathrm{mM}$ Pefablock), and incubated for $10 \mathrm{~min}$ on ice. Swollen cells were homogenized with 10 strokes in two volumes Roeder A buffer, and the homogenate was centrifuged for $10 \mathrm{~min}$ at $900 \mathrm{~g}$. The remaining nuclei pellet was washed once in PBS and subsequently homogenized with 15 strokes in Roeder C buffer (20 mM HEPES, pH 7.9; 420 mM KCl; $1.5 \mathrm{mM} \mathrm{MgCl}$; $0.5 \mathrm{mM}$ DTT; $5 \%$ glycerine; $0.2 \mathrm{mM}$ EDTA; and 1 $\mathrm{mM}$ Pefablock). Nuclear extract was cleared at 17,000g for $30 \mathrm{~min}$.

For Western blot analysis, proteins were separated by $10 \%$ SDSPAGE and transferred onto nitrocellulose membrane (Amersham Bioscience). Membranes were blocked for $30 \mathrm{~min}$ in Western blot wash buffer (30 mM Tris-HCl, pH 7.5; $150 \mathrm{mM} \mathrm{NaCl;0.25 \%} \mathrm{[v/v]}$ Tween-20) containing $10 \%(\mathrm{w} / \mathrm{v})$ dry milk (Roth) and subsequently treated with the corresponding antibodies. The monoclonal anti-Ago2(11A9) was generated in cooperation with E. Kremmer as described previously (Beitzinger et al. 2007). Hybridoma supernatant was diluted 1:50 for Western blotting. Commercial antibodies additionally used include monoclonal anti-HA antibody (HISS Diagnostics), monoclonal anti-myc antibody (Abcam), and anti-S6 ribosomal protein antibody (Cell Signaling Technologies), as well as peroxidase-conjugated secondary anti-rat IgG antibody (Jackson Lab), anti-mouse IgG antibody (Sigma), and anti-rabbit IgG antibody (Sigma). They were diluted according to the manufacturers' recommendations for Western blotting.

\section{Immunoprecipitations and peptide elution experiments}

Tagged proteins were immunoprecipitated from total cell extract using anti-Flag- or anti-myc-conjugated agarose beads (both Sigma). For precipitation of untagged proteins, saturating amounts of the corresponding antibodies were coupled to protein $\mathrm{G}$ sepharose beads (Amersham Bioscience) for $2 \mathrm{~h}$ at $4^{\circ} \mathrm{C}$ prior to immunoprecipitation.

Beads and an excess of total extract were incubated for $90 \mathrm{~min}$ at $4^{\circ} \mathrm{C}$ under slight rotation. Precipitates were washed twice with IP wash buffer (IPB; $50 \mathrm{mM}$ Tris- $\mathrm{HCl}, \mathrm{pH}$ 7.5; $300 \mathrm{mM} \mathrm{NaCl}$; $5 \mathrm{mM} \mathrm{Mg} 2 \mathrm{Cl}$; and $0.05 \%$ Nonidet P-40), once with PBS, and finally transferred to a new tube and resuspended in the appropriate buffer.

Native RISC was captured with anti-Ago2(11A9) bound to protein $G$ sepharose during a standard immunoprecipitation procedure (see above) and stringently washed: Twice with IPB containing $0.5 \mathrm{M} \mathrm{NaCl}$, followed by a 40 -min incubation in the 
presence of $360 \mathrm{mM} \mathrm{NaCl}$ at $4^{\circ} \mathrm{C}$ under rotation, and one final washing with $0.5 \mathrm{M} \mathrm{NaCl}$. RISC precipitates were equilibrated in PBS and eluted with $100 \mu \mathrm{g}$ of synthetic Ago2 peptide in IPB per $25 \mu \mathrm{L}$ of beads at $25^{\circ} \mathrm{C}$ and $600 \mathrm{rpm}$ for $90 \mathrm{~min}$. Eluate was collected with a polyprep column (Biorad) equilibrated with IPB. Ago2 complexes that remained on the beads were finally eluted with $0.1 \mathrm{M}$ glycine $\mathrm{pH} 2.3$ and neutralized immediately after with 1 M Tris-HCl, $\mathrm{pH} 8.0$.

To test the effect of different $\mathrm{pH}$ values on RISC elution, Ago2 peptide was solved in IPB of the respective $\mathrm{pH}$.

For time course experiments, the elution reaction was incubated directly in the polyprep column. For each time point, the eluate was collected and an aliquot stored at $-20^{\circ} \mathrm{C}$ while the remaining reaction mixture was re-added into the column.

\section{In vitro RISC assays}

Preparation of $\mathrm{cap}^{32}{ }^{32} \mathrm{P}$-labeled RNA used as RISC substrate was described earlier (Martinez et al. 2002). The sequence of the exogenous siRNA used in Figure 2C is UCGAAGUAUUCCGC GUACGUdT (Meister et al. 2004). Assays were performed with $40 \%(\mathrm{v} / \mathrm{v})$ RISC either eluted or bound to beads in a total volume of $25 \mu \mathrm{L}$ with $40 \mathrm{mM} \mathrm{KCl}, 4 \mathrm{mM} \mathrm{Mg}_{2} \mathrm{Cl}_{2}, 5 \mathrm{mM}$ DTT, $1 \mathrm{mM} \mathrm{ATP}$, $0.2 \mathrm{mM}$ GTP, and 1.2 U RiboLock RNase inhibitor (Fermentas). After adding $1 \mu \mathrm{L}$ of substrate RNA $\left(1.5 \mathrm{~Bq} / \mathrm{cm}^{2}\right)$, samples were incubated for $90 \mathrm{~min}$ at $30^{\circ} \mathrm{C}$. RNA extraction and analysis was described before (Meister et al. 2004).

\section{Northern blotting}

Total RNA was extracted from HEK 293 cells according to LagosQuintana et al. (2001). Coimmunoprecipitated RNA was isolated by Proteinase K (AppliChem) treatment, followed by two extraction steps using first acidic phenol and second chloroform. For RNA precipitation, aqueous phase was mixed with three volumes of absolute ethanol and incubated overnight at $-20^{\circ} \mathrm{C}$. Without any additional washing, RNA was finally solved in formamide loading dye, separated by electrophoresis on 15\% denaturing polyacrylamide gels, and transferred to Hybond-N membrane (Amersham Bioscience) by semidry blotting for 25 min with $5 \mathrm{~V}$. Membranes were dried, UV treated, and incubated for $1 \mathrm{~h}$ at $80^{\circ} \mathrm{C}$. Prehybridization was performed in $5 \times$ SSC; $20 \mathrm{mM} \mathrm{Na}_{2} \mathrm{HPO}_{4}$, pH 7.2; 7\% (w/v) SDS; Denhardt's solution $(0.02 \%[\mathrm{w} / \mathrm{v}]$ bovine serum albumin V; $0.02 \%$ [w/v] Polyvinylpyrrolidone K30; $0.02 \%$ [w/v] Ficoll 400), and $0.1 \mathrm{mg} / \mathrm{mL}$ sonicated salmon sperm DNA for $1 \mathrm{~h}$ at $45^{\circ} \mathrm{C}$ before a $5^{\prime}-{ }^{32} \mathrm{P}$-labeled probe (see below) was added overnight. Subsequently, the membrane was washed in 10min intervals twice with $5 \times$ SSC; $1 \%(w / v)$ SDS and once with $1 x$ SSC; $1 \%(w / v)$ SDS. Exposure to Kodak BioMax MS films was performed with an intensifying screen (Kodak) at $-80^{\circ} \mathrm{C}$.

For Northern probe preparation, 20 pmol synthetic DNAoligonucleotides (Metabion) reverse complementary to miR-19b were radiolabeled in a T4-Polynucleotide kinase (Fermentas) reaction in the presence of $\gamma-{ }^{32} \mathrm{P}$-ATP (GE Healthcare) according to standard protocols and subsequently purified by gel filtration using MicroSpin G-25 columns (Amersham Bioscience).

\section{Immunofluorescence}

Cells were grown to $60 \%-70 \%$ confluency on cover slips and fixed with $3.7 \%$ formaldehyde in PBS. After $15 \mathrm{~min}$ of fixation, the reaction was stopped by addition of $100 \mathrm{mM}$ glycine solved in PBS. Subsequently, cells were incubated $10 \mathrm{~min}$ in PBS with $3 \%$ $(\mathrm{w} / \mathrm{v})$ bovine serum albumin (BSA, Roth) and $0.2 \%(\mathrm{v} / \mathrm{v})$ Triton X 100 to make them permeable as well as to block unspecific antibody binding. After rinsing with $0.1 \%(\mathrm{v} / \mathrm{v})$ Tween-20 and $0.2 \%(\mathrm{w} / \mathrm{v})$ BSA, primary antibodies were added for $1 \mathrm{~h}$. After intensive washing, secondary antibodies were added for another hour in the dark. DNA was stained with DAPI at a final concentration of $1 \mu \mathrm{g} / \mathrm{mL}$ for a few minutes. Immunofluorescence was observed and recorded using a LEICA TCS SP2 Confocal Laser Scanning microscope and Leica Confocal Software softWoRx. Monoclonal anti-LSm4 antibody was purchased from Geneway, FITC-conjugated anti-chicken IgY antibody from Sigma, and TexasRed-conjugated anti-rat IgG antibody from Vector Laboratories.

\section{siRNA transfection}

HeLa cells were reverse transfected with siRNAs in six-well plates at $40 \mathrm{nM}$ final concentration using RNAiMAX (Invitrogen), according to the manufacturer's instructions. After $2 \mathrm{~d}$, cells were seeded to cover slips in six-well plates. Cells were fixed $5 \mathrm{~d}$ posttransfection and stained for Ago 2 and LSm4 (see above). The following siRNAs were used (sense, antisense): Ago2 siRNA, 5' GCACGGAAGUCCAUCUGAAUU, 5'-UUCAGAUGGACUUCC GUGCUU; non-silencing control siRNA, 5'-UUGUCUUGCAU UCGACUAAUT, 5'-UUAGUCGAAUGCAAGACAAUT.

\section{ACKNOWLEDGMENTS}

We thank Sabine Rottmüller for technical assistance, Ralf Zenke for help with the confocal microscope, Christian Pohl for discussion, and Stefan Jentsch for support. This work was supported in part by the Deutsche Forschungsgemeinschaft (DFG, Me2064/2-1), the European Union (LSHG-CT-2006037900), and the Max Planck Society. L.W. received a fellowship from the Boehringer Ingelheim Fonds.

Received December 21, 2007; accepted February 18, 2008.

\section{REFERENCES}

Behm-Ansmant, I., Rehwinkel, J., Doerks, T., Stark, A., Bork, P., and Izaurralde, E. 2006. mRNA degradation by miRNAs and GW182 requires both CCR4:NOT deadenylase and DCP1:DCP2 decapping complexes. Genes \& Dev. 20: 1885-1898.

Beitzinger, M., Peters, L., Zhu, J.Y., Kremmer, E., and Meister, G. 2007. Identification of human microRNA targets from isolated Argonaute protein complexes. RNA Biol. 4: 76-84.

Bhattacharyya, S.N., Habermacher, R., Martine, U., Closs, E.I., and Filipowicz, W. 2006. Relief of microRNA-mediated translational repression in human cells subjected to stress. Cell 125: 1111-1124.

Carmell, M.A., Xuan, Z., Zhang, M.Q., and Hannon, G.J. 2002. The Argonaute family: Tentacles that reach into RNAi, developmental control, stem cell maintenance, and tumorigenesis. Genes \& Dev. 16: $2733-2742$.

Chen, P.Y. and Meister, G. 2005. microRNA-guided post-transcriptional gene regulation. Biol. Chem. 386: 1205-1218.

Chendrimada, T.P., Gregory, R.I., Kumaraswamy, E., Norman, J., Cooch, N., Nishikura, K., and Shiekhattar, R. 2005. TRBP recruits the Dicer complex to Ago2 for microRNA processing and gene silencing. Nature 436: 740-744.

Dignam, J.D., Lebovitz, R.M., and Roeder, R.G. 1983. Accurate transcription initiation by RNA polymerase II in a soluble extract 
from isolated mammalian nuclei. Nucleic Acids Res. 11: 1475-1489. doi: 10.1093/nar/11.5.1475.

Ding, L., Spencer, A., Morita, K., and Han, M. 2005. The developmental timing regulator AIN-1 interacts with miRISCs and may target the argonaute protein ALG-1 to cytoplasmic P bodies in C. elegans. Mol. Cell 19: 437-447.

Easow, G., Teleman, A.A., and Cohen, S.M. 2007. Isolation of microRNA targets by miRNP immunopurification. RNA 13: 1198-1204.

Eulalio, A., Behm-Ansmant, I., and Izaurralde, E. 2007a. P bodies: At the crossroads of post-transcriptional pathways. Nat. Rev. Mol. Cell Biol. 8: 9-22.

Eulalio, A., Behm-Ansmant, I., Schweizer, D., and Izaurralde, E. 2007b. P-body formation is a consequence, not the cause, of RNAmediated gene silencing. Mol. Cell. Biol. 27: 3970-3981.

Filipowicz, W., Jaskiewicz, L., Kolb, F.A., and Pillai, R.S. 2005. Posttranscriptional gene silencing by siRNAs and miRNAs. Curr. Opin. Struct. Biol. 15: 331-341.

Giraldez, A.J., Mishima, Y., Rihel, J., Grocock, R.J., Van Dongen, S., Inoue, K., Enright, A.J., and Schier, A.F. 2006. Zebrafish MiR-430 promotes deadenylation and clearance of maternal mRNAs. Science 312: 75-79.

Gregory, R.I., Chendrimada, T.P., Cooch, N., and Shiekhattar, R. 2005. Human RISC couples microRNA biogenesis and posttranscriptional gene silencing. Cell 123: 631-640.

Haase, A.D., Jaskiewicz, L., Zhang, H., Laine, S., Sack, R., Gatignol, A., and Filipowicz, W. 2005. TRBP, a regulator of cellular PKR and HIV-1 virus expression, interacts with Dicer and functions in RNA silencing. EMBO Rep. 6: 961-967.

Hall, T.M. 2005. Structure and function of argonaute proteins. Structure 13: 1403-1408.

Hock, J., Weinmann, L., Ender, C., Rudel, S., Kremmer, E., Raabe, M., Urlaub, H., and Meister, G. 2007. Proteomic and functional analysis of Argonaute-containing mRNA-protein complexes in human cells. EMBO Rep. 8: 1052-1060.

Hutvagner, G. and Simard, M.J. 2008. Argonaute proteins: Key players in RNA silencing. Nat. Rev. Mol. Cell Biol. 9: 22-32.

Jakymiw, A., Lian, S., Eystathioy, T., Li, S., Satoh, M., Hamel, J.C., Fritzler, M.J., and Chan, E.K. 2005. Disruption of GW bodies impairs mammalian RNA interference. Nat. Cell Biol. 7: 12671274.

Janowski, B.A., Huffman, K.E., Schwartz, J.C., Ram, R., Nordsell, R., Shames, D.S., Minna, J.D., and Corey, D.R. 2006. Involvement of AGO1 and AGO2 in mammalian transcriptional silencing. Nat. Struct. Mol. Biol. 13: 787-792.

Jin, P., Zarnescu, D.C., Ceman, S., Nakamoto, M., Mowrey, J., Jongens, T.A., Nelson, D.L., Moses, K., and Warren, S.T. 2004. Biochemical and genetic interaction between the fragile X mental retardation protein and the microRNA pathway. Nat. Neurosci. 7: 113-117.

Karginov, F.V., Conaco, C., Xuan, Z., Schmidt, B.H., Parker, J.S., Mandel, G., and Hannon, G.J. 2007. A biochemical approach to identifying microRNA targets. Proc. Natl. Acad. Sci. 104: 1929119296.

Kim, D.H., Villeneuve, L.M., Morris, K.V., and Rossi, J.J. 2006. Argonaute-1 directs siRNA-mediated transcriptional gene silencing in human cells. Nat. Struct. Mol. Biol. 13: 793-797.

Lagos-Quintana, M., Rauhut, R., Lendeckel, W., and Tuschl, T. 2001. Identification of novel genes coding for small expressed RNAs. Science 294: 853-858.

Lee, Y., Hur, I., Park, S.Y., Kim, Y.K., Suh, M.R., and Kim, V.N. 2006. The role of PACT in the RNA silencing pathway. EMBO J. 25: $522-532$.

Leung, A.K., Calabrese, J.M., and Sharp, P.A. 2006. Quantitative analysis of Argonaute protein reveals microRNA-dependent localization to stress granules. Proc. Natl. Acad. Sci. 103: 18125-18130.

Leuschner, P.J., Ameres, S.L., Kueng, S., and Martinez, J. 2006. Cleavage of the siRNA passenger strand during RISC assembly in human cells. EMBO Rep. 7: 314-320.
Liu, J., Carmell, M.A., Rivas, F.V., Marsden, C.G., Thomson, J.M., Song, J.J., Hammond, S.M., Joshua-Tor, L., and Hannon, G.J. 2004. Argonaute 2 is the catalytic engine of mammalian RNAi. Science 305: 1437-1441.

Liu, J., Rivas, F.V., Wohlschlegel, J., Yates 3rd, J.R., Parker, R., and Hannon, G.J. 2005a. A role for the P-body component GW182 in microRNA function. Nat. Cell Biol. 7: 1161-1166.

Liu, J., Valencia-Sanchez, M.A., Hannon, G.J., and Parker, R. 2005b. MicroRNA-dependent localization of targeted mRNAs to mammalian P-bodies. Nat. Cell Biol. 7: 719-723.

Ma, J.B., Yuan, Y.R., Meister, G., Pei, Y., Tuschl, T., and Patel, D.J. 2005. Structural basis for $5^{\prime}$-end-specific recognition of guide RNA by the A. fulgidus Piwi protein. Nature 434: 666-670.

Maniataki, E. and Mourelatos, Z. 2005. A human, ATP-independent, RISC assembly machine fueled by pre-miRNA. Genes \& Dev. 19: 2979-2990.

Martinez, J., Patkaniowska, A., Urlaub, H., Lührmann, R., and Tuschl, T. 2002. Single-stranded antisense siRNAs guide target RNA cleavage in RNAi. Cell 110: 563-574.

Matranga, C., Tomari, Y., Shin, C., Bartel, D.P., and Zamore, P.D. 2005. Passenger-strand cleavage facilitates assembly of siRNA into Ago2-containing RNAi enzyme complexes. Cell 123: 607620.

Meister, G. and Tuschl, T. 2004. Mechanisms of gene silencing by double-stranded RNA. Nature 431: 343-349.

Meister, G., Landthaler, M., Patkaniowska, A., Dorsett, Y., Teng, G., and Tuschl, T. 2004. Human Argonaute2 mediates RNA cleavage targeted by miRNAs and siRNAs. Mol. Cell 15: 185-197.

Meister, G., Landthaler, M., Peters, L., Chen, P.Y., Urlaub, H., Luhrmann, R., and Tuschl, T. 2005. Identification of novel argonaute-associated proteins. Curr. Biol. 15: 2149-2155.

Morris, K.V., Chan, S.W., Jacobsen, S.E., and Looney, D.J. 2004. Small interfering RNA-induced transcriptional gene silencing in human cells. Science 305: 1289-1292.

Mourelatos, Z., Dostie, J., Paushkin, S., Sharma, A., Charroux, B., Abel, L., Rappsilber, J., Mann, M., and Dreyfuss, G. 2002. miRNPs: A novel class of ribonucleoproteins containing numerous microRNAs. Genes \& Dev. 16: 720-728.

Parker, J.S. and Barford, D. 2006. Argonaute: A scaffold for the function of short regulatory RNAs. Trends Biochem. Sci. 31: 622630.

Parker, J.S., Roe, S.M., and Barford, D. 2004. Crystal structure of a PIWI protein suggests mechanisms for siRNA recognition and slicer activity. EMBO J. 23: 4727-4737.

Parker, J.S., Roe, S.M., and Barford, D. 2005. Structural insights into mRNA recognition from a PIWI domain-siRNA guide complex. Nature 434: 663-666.

Patel, D.J., Ma, J.B., Yuan, Y.R., Ye, K., Pei, Y., Kuryavyi, V., Malinina, L., Meister, G., and Tuschl, T. 2006. Structural biology of RNA silencing and its functional implications. Cold Spring Harb. Symp. Quant. Biol. 71: 81-93.

Peters, L. and Meister, G. 2007. Argonaute proteins: Mediators of RNA silencing. Mol. Cell 26: 611-623.

Pillai, R.S., Bhattacharyya, S.N., Artus, C.G., Zoller, T., Cougot, N., Basyuk, E., Bertrand, E., and Filipowicz, W. 2005. Inhibition of translational initiation by Let-7 MicroRNA in human cells. Science 309: 1573-1576.

Pillai, R.S., Bhattacharyya, S.N., and Filipowicz, W. 2007. Repression of protein synthesis by miRNAs: How many mechanisms? Trends Cell Biol. 17: 118-126.

Rand, T.A., Petersen, S., Du, F., and Wang, X. 2005. Argonaute2 cleaves the anti-guide strand of siRNA during RISC activation. Cell 123: 621-629.

Robb, G.B. and Rana, T.M. 2007. RNA helicase A interacts with RISC in human cells and functions in RISC loading. Mol. Cell 26: 523537.

Robb, G.B., Brown, K.M., Khurana, J., and Rana, T.M. 2005. Specific and potent RNAi in the nucleus of human cells. Nat. Struct. Mol. Biol. 12: 133-137. 
Salzman, D.W., Shubert-Coleman, J., and Furneaux, H. 2007. P68 RNA helicase unwinds the human let-7 microRNA precursor duplex and is required for let-7-directed silencing of gene expression. J. Biol. Chem. 282: 3277332779.

Sen, G.L. and Blau, H.M. 2005. Argonaute 2/RISC resides in sites of mammalian mRNA decay known as cytoplasmic bodies. Nat. Cell Biol. 7: 633-636.

Song, J.J. and Joshua-Tor, L. 2006. Argonaute and RNA-Getting into the groove. Curr. Opin. Struct. Biol. 16: 5-11.
Song, J.J., Smith, S.K., Hannon, G.J., and Joshua-Tor, L. 2004. Crystal structure of Argonaute and its implications for RISC slicer activity. Science 305: 1434-1437.

Till, S., Lejeune, E., Thermann, R., Bortfeld, M., Hothorn, M., Enderle, D., Heinrich, C., Hentze, M.W., and Ladurner, A.G. 2007. A conserved motif in Argonaute-interacting proteins mediates functional interactions through the Argonaute PIWI domain. Nat. Struct. Mol. Biol. 14: 897-903.

Zamore, P.D. and Haley, B. 2005. Ribo-gnome: The big world of small RNAs. Science 309: 1519-1524. 

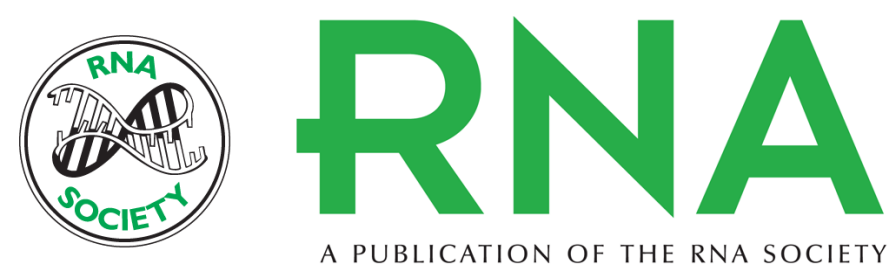

A PUBLICATION OF THE RNA SOCIETY

\section{A multifunctional human Argonaute2-specific monoclonal antibody}

Sabine Rüdel, Andrew Flatley, Lasse Weinmann, et al.

RNA 2008 14: 1244-1253

References This article cites 55 articles, 19 of which can be accessed free at:

http://rnajournal.cshlp.org/content/14/6/1244.full.html\#ref-list-1

License

Email Alerting Receive free email alerts when new articles cite this article - sign up in the box at the Service top right corner of the article or click here.

To subscribe to $R N A$ go to:

http://rnajournal.cshlp.org/subscriptions 